\title{
Tsafon
}

Revue d'études juives du Nord

$72 \mid 2016$

Juifs, Israéliens, dans la littérature française et israélienne

\section{La traduction intégrale du Talmud de Babylone en italien}

\author{
Claude Cazalé Bérard
}

\section{(2) OpenEdition \\ Journals}

Édition électronique

URL : https://journals.openedition.org/tsafon/464

DOI : $10.4000 /$ tsafon.464

ISSN : 2609-6420

Éditeur

Association Jean-Marie Delmaire

Édition imprimée

Date de publication : 1 décembre 2016

Pagination : 165-166

ISSN : $1149-6630$

Référence électronique

Claude Cazalé Bérard, "La traduction intégrale du Talmud de Babylone en italien », Tsafon [En ligne], 72 | 2016, mis en ligne le 31 mai 2018, consulté le 25 juin 2021. URL : http://journals.openedition.org/ tsafon/464 ; DOI : https://doi.org/10.4000/tsafon.464 


\section{Informations......}

\section{La traduction intégrale du Talmud de Babylone en italien par Claude Cazalé Bérard}

Un événement exceptionnel a marqué le printemps romain, exactement à la date du 5 avril 2016, après des siècles de censure et de destructions : la présentation du premier volume de la traduction intégrale du Talmud de Babylone en italien, dans le cadre prestigieux de l'Accademia Nazionale dei Lincei, en présence du Président de la République italienne, Sergio Mattarella, auquel a été remis un exemplaire du premier traité du Talmud de Babylone, Rosh ha-Shanà, et en présence du rav. Adin Steinsaltz, qui préside le Comité d'Honneur, entourés des autorités politiques et religieuses institutionnelles, des représentants de la culture et des arts italiens.

L'aboutissement d'un tel projet, dans sa toute première étape, prouve déjà la volonté de transmettre aux nouvelles générations une tradition millénaire, une mémoire précieusement conservée tout au long des siècles en dépit des interdits, des persécutions, des dispersions, des exils, et qui désormais va être relayée par les technologies les plus avancées. Mais cette réalisation prouve aussi la volonté de sauvegarder un patrimoine de connaissances et de pensée qui appartient à plein titre à notre tradition et à l'histoire humaine dans son universalité, justement par delà les frontières culturelles et linguistiques. Cette tentative répond aussi au souci très actuel de lutter contre l'analphabétisme religieux et l'ignorance des fondements mêmes de notre civilisation menacée par le retour de la barbarie.

Cette vaste et ambitieuse entreprise, née en 2011 à l'initiative du professeur Clélia Piperno, coordonnée par le grand rabbin de Rome, rav. Riccardo Di Segni et soutenue par l'État italien (Présidence du Conseil, Ministères, CNR...), l'Union des Communautés Juives italiennes, le Collège Rabbinique, l'université de Rome 2, prévoit la publication de trente volumes confiée à la maison d'édition Giuntina de Florence, spécialisée dans les domaines des études hébraïques, des littératures juives et israéliennes.

Le Comité scientifique et l'équipe éditoriale qui regroupe une cinquantaine de spécialistes, chercheurs, traducteurs, rédacteurs, informaticiens (puisque la réalisation du projet repose sur le traitement numérique des phases de traduction, de rédaction et d'édition des textes assuré par l'Institut de linguistique numérique du CNR, qui a mis au point le software "Traduco ») travaillent en continu dans une dynamique hautement collaborative sur un corpus de treize traités, la publication des textes étant assortie d'une documentation explicative scientifique, linguistique et historique. Il s'agit en même temps d'une véritable école de formation à l'approche et à la traduction de ces textes, 
pour de jeunes chercheurs, en réponse à une toute nouvelle soif de connaissance, à un intérêt croissant qui se sont manifestés parmi les nouvelles générations, notamment pour une œuvre telle que le Talmud, qui propose plusieurs niveaux de lecture et d'interprétation: outre recueillir une multiplicité de savoirs (juridique, scientifique, philosophique, littéraire, exégétique, homilétique...), les traités qui le composent présentent une stratification rédactionnelle, des commentaires et des débats contradictoires sans fin, qui ouvrent un champ de recherche pratiquement inépuisable.

Clélia Piperno interrogée par Pagine ebraiche (www.paginebraiche.it) insiste sur le fait qu'il ne s'agissait pas d'obtenir de l'État italien une sorte de réparation des lois raciales fascistes de 1938, ni même d'obtenir une reconnaissance (tardive) de la valeur intrinsèque d'une culture juive marginalisée pendant des siècles, bien au contraire il s'agit d'un pari sur le futur: " Nous devons comprendre qu'il n'y a pas seulement le culte de la mémoire de la Shoah, mais que nous avons le devoir de transmettre notre patrimoine culturel avec notre enseignement : c'est précisément ce qu'est le Talmud » (n.4, avril 2016).

Quelques éléments et dates à retenir

Le Talmud de Babylone (Loi orale : Mishna et Gemara, rédaction en hébreu et araméen conclue avant l'an 499) eut sa première édition à Venise en 1520-1523 par l'imprimeur Daniel Bomberg : or le modèle typographique adopté par cet imprimeur pionnier - avec le texte de la Mishna au centre et les commentaires autour - est celui qui fut définitivement retenu.

La réception du Talmud dans le monde chrétien

- La première condamnation du Talmud remonte à la Bulle d'Innocent IV, Impia Judeorum perfidia, en 1244, transmise au roi de France Louis IX (Saint-Louis) : lequel avait déjà procédé à des confiscations et fait brûler publiquement, en 1242, vingt-quatre chariots remplis de livres en hébreu (Talmud et autres écrits). D'autres bûchers furent dressés, en 1309 à Paris et en 1319 à Toulouse.

- Le 12 août 1553, le pape Jules II ordonna par décret la destruction du Talmud : ainsi, à Rome, le 9 septembre 1553, un nouveau bûcher fut dressé, place Campo dei Fiori ; et de même le 21 octobre 1553, sur ordre du Conseil des Dix, à Venise, place Saint Marc, et encore toujours dans la même ville en 1568. Ensuite l'impression de livres en hébreu fut de nouveau autorisée.

- En 1746, le pape Benoît XIV renouvela la juridiction contre les Juifs et l'interdiction du Talmud.

- Le 5 avril 1775, le pape Pie VI, avec un décret très répressif, réduisit encore les droits et la liberté des Juifs.

- Tandis que les guerres napoléoniennes entraînent l'émancipation des Juifs, avec l'entrée des Français à Rome, en 1810, l'imprimatur est accordé pour le premier livre imprimé en hébreu dans la ville.

- Toutefois le Congrès de Vienne (1814-1815) rétablit les gouvernements d'Ancien régime, et par conséquent la condition de sujétion des Juifs : le ghetto de Rome est à nouveau fermé, et les activités économiques, intellectuelles et culturelles autorisées sont à nouveau interdites.

- Lors des guerres pour l'indépendance de l'Italie, jusqu'à l'Unité et à la prise de Rome, annexée à l'Italie et choisie comme capitale, les Juifs se sont engagés très activement dans la vie politique : ce qui aboutira à l'élection de Ernesto Nathan, mazzinien, républicain et franc-maçon, comme maire de Rome (1907-1913). 